Rheumatoid arthritis

\section{Dynamic exercises in patients with rheumatoid arthritis}

\section{A P Anandarajah, E M Schwarz}

\author{
Are they friend or foe?
}

$\mathrm{R}$ heumatoid arthritis (RA) is an inflammatory disease characterised by the presence of synovial inflammation and destruction of bone and cartilage. This matrix degradation leads to reduced physical function. Indeed, up to $50 \%$ of patients display a decreased range of movement at initial presentation to a rheumatologist. ${ }^{1}$ The presence of widespread synovial inflammation, coupled with impaired mobility and function, results in a low bone mass.

Two distinct forms of bone losslocalised and generalised-have been described. ${ }^{2}$ Localised bone loss in the form of bone erosions and periarticular osteopenia is an important component of the radiographic criteria for the diagnosis of RA. ${ }^{3}$ More severe disease activity is usually associated with the presence of extensive erosions. Erosions typically develop within the first 2 years of diagnosis of RA. ${ }^{4}$ The rate of progression of these erosions is, however, less clear. Whereas some studies suggest that radiographic progression continues at a constant rate throughout the disease, ${ }^{5}$ others report a variable course. ${ }^{67}$ Synovial inflammation is an important determinant of progression of erosive changes in RA; however, radiological progression does not strongly correlate with other clinical measures. ${ }^{8}$

\section{"Rheumatologists often recommend non-weightbearing exercise"}

Exercise is an essential component of medical and surgical management of inflammatory joint diseases. Nevertheless, rheumatologists traditionally have recommended exercise restriction or exercise programmes limited to nonweightbearing isometric exercises and range of motion exercises owing to concerns about aggravating joint inflammation and accelerating joint damage in patients with RA. ${ }^{9-11}$ In contrast with the standard regimens, dynamic exercises promote muscle movement during joint motion or aerobic activities, or both. Examples of dynamic exercise activities include swimming, walking, crosscountry skiing, bicycling, weight training, and house cleaning.
Several studies have demonstrated that dynamic exercises improve muscle function and aerobic capacity ${ }^{12-16}$ without negatively affecting the disease process $^{12} 1316-18$ in patients with RA. Moreover, muscle strength and joint mobility improve in patients with RA who participate in dynamic exercise, whether they have active ${ }^{19}$ or inactive disease. $^{20}$ Based on the studies cited above, the American College of Rheumatology recommends regular participation in dynamic exercise programmes in their recent update of treatment guidelines for RA. ${ }^{21}$

In this issue of the Annals of the Rheumatic Diseases, de Jong and colleagues report on the effect of long term, high intensity, weightbearing exercises on radiological damage of the joints of the hands and feet in patients with RA. ${ }^{22}$ A total of 136 patients in a high intensity exercise group were compared with 145 patients receiving usual care physical therapy for progression of radiological damage, over 2 years. The exercise group participated in 75 minute sessions of group exercises, twice a week. The exercise programme included bicycle training, exercises intended to improve muscle strength, joint mobility, and activities of daily living, and a sport such as soccer, badminton, volleyball, or basketball. Participants in the control group were treated by a physical therapist as deemed necessary by the patient's physician. High intensity weightbearing exercises, however, were not allowed in this group.

Both groups were matched for age, disease duration, disease activity, rheumatoid factor positivity, and use of disease modifying antirheumatic drugs (DMARDs). Radiological damage was assessed at the wrists, and small joints of the hands and feet ( 32 joints) at baseline, 12 months, and 24 months. A single observer scored these joints based on the modified Larsen method. Although an increase in radiological damage was noted in both groups at 2 years, significantly less progression was recorded in the high intensity exercise group. The rate of progression was particularly reduced in the joints of the feet. Based on these findings the authors conclude that high intensity exercises do not increase radiological damage and might even retard the progression of joint damage in the feet.

$$
\begin{aligned}
& \text { "High intensity exercise may retard } \\
& \text { joint damage progression in the } \\
& \text { feet" }
\end{aligned}
$$

In the past three decades, attempts have been made to study the role of exercise programmes on radiographic progression. There are, however, only a few well designed studies assessing the long term effects of high intensity exercises on radiological joint damage in patients with RA. None of these studies showed an increase in the rate of radiological damage in patients following dynamic exercises programmes. Only one of these studies reported a significant reduction in disease progression with an exercise programme

Nordemar et al reported significantly more pronounced radiographic progression in patients with RA not on an exercise programme than in those following a regular, supervised exercise programme. ${ }^{12}$ In their study 46 patients were randomly assigned to either group, matched for age, disease duration, and disease activity. Most patients in the exercise group participated in group training sessions for a period of $60 \mathrm{~min}$ utes, conducted by a physical therapist, every other week. The exercise regimen included cycling, swimming, skiing, dancing, gymnastics, golf, jogging, and other organised training sports. Radiographs of symptomatic joints of the feet were evaluated based on the Larsen scoring method before and after the study. Patients were followed up for a mean period of 5.4 years. The validity of this study is, however, questionable as some patients were allowed to cross over between the exercise and no exercise groups. Furthermore, the numbers in each group were small.

Hakkinen et al did not detect a significant difference in joint damage, between those following a dynamic exercise programme and those on range of motion exercises, in a well designed, randomised, controlled trial. ${ }^{23}$ Seventy patients with recent onset RA were randomly assigned to either a dynamic strength training group or a control group. The first group was trained in exercises for the upper and lower extremities as well as for abdominal and back muscles. Patients were instructed to do these exercises for 45 minutes, twice a week. They were also encouraged to take part in recreational physical activities, such as walking, cycling, skiing, and swimming two to three times a week. Patients in the 
control group were allowed to perform range of motion and stretching exercises twice a week and were free to continue their recreational physical activities. Patients were well matched for duration of disease, age, rheumatoid factor positivity, disease activity (as measured by the 28 joint Disease Activity Score (DAS28)), and extent of joint damage. Radiographic damage in joints of the hands and feet (30 joints) was scored by the Larsen method. $x$ Ray examinations were made at baseline, 1 year, and after 2 years. None of the patients had been treated with glucocorticoids or DMARDs at the time of recruitment. All patients had disease duration of less than 12 months and all patients started treatment with DMARDs at the onset of the trial. Although joint damage increased slightly in both groups, no significant difference was noted between the two groups at 2 years. A recent follow up on this study continued to show no difference in radiological damage between the two groups after 5 years. ${ }^{24}$

\section{"Many studies are too small for conclusions to be drawn about the effect of exercise on radiological damage"}

It is hard to draw conclusions from other studies owing to their poor design and small numbers. An earlier study by Hakkinen et al attempted to study the effects of short term dynamic exercises in patients with recent onset $\mathrm{RA}^{25}$ It included patients with RA and psoriatic arthritis (PsA) and provided no information on drug treatment or on the number of patients with RA or PsA. A study by Hansen et al had small numbers and did not provide information on disease duration, rheumatoid factor status, and on drugs. ${ }^{18}$ An observational study by Nordemar et al reported on just 10 patients and assessed only $x$ ray findings of the knees. ${ }^{26}$

Recently, de Jong et al have reported on progression of radiological damage in large joints following high intensity exercise programmes ${ }^{27}$ done as part of the study in the current report. ${ }^{22}$ Two readers, using the Larsen method, scored radiographs of shoulders, elbows, hips, knees, ankles, and subtalar joints. No significant difference was noted between the exercise group and the control groups at 24 months, but a trend toward more damage was seen in the latter. Furthermore, patients with more baseline damage were slightly more likely to show progression. Increased damage was also noted more often in patients with longer disease duration.
The conflicting results between the Hakkinen study ${ }^{23}$ and the de Jong study $^{22}$ are not easily explained. Participants in the Hakkinen trial had early onset RA and were aggressively treated with DMARDs early in the disease course. Early treatment with DMARDs may indeed inhibit or retard radiological damage. ${ }^{28}$ Participants in the de Jong study, on the other hand, had an average disease duration of 6 years. Many reports have shown that a delay in initiating DMARD treatment can adversely affect various disease measures years later. ${ }^{29-31}$ Furthermore, recent reports have shown that a larger increase in radiographic score occurs during the first 5 years. ${ }^{32}$ Although over $85 \%$ of the participants in the de Jong trial were receiving DMARDs, the starting dates of these agents were not reported. Radiological damage at baseline also appears to have been greater in this study than in the study by Hakkinen et al The previous study by de Jong et al looking at the effect of exercises on large joints does suggest that patients with more joint damage at baseline are indeed the ones more likely to progress. The patients in the two studies are therefore not directly comparable. The presence of the multiple variables also demonstrates the difficulty in designing a study to evaluate the effect of exercise on radiological progression in RA.

The pathophysiology of the way in which high intensity exercise programmes might retard radiographic progression is not well understood. Earlier trials suggested the possibility of exercise related changes in synovial circulation, ${ }^{33}$ but recent studies propose that exercises suppress the inflammatory process by altering the cytokine profile. Interestingly, de Jong and colleagues had also reported an improvement in bone mineral density scores with high intensity weightbearing exercises in the same group of patients as in the current report. ${ }^{34}$ This, together with the finding that radiological progression is retarded, might provide further credence to the suggestion that osteoporosis and bone erosions have a common denominator. Indeed, published reports suggest that both conditions are mediated by the cellular action of osteoclasts $^{35}$ and result from a negative remodelling balance secondary to increased bone resorption. ${ }^{36}$ Osteoclast formation, activity, and survival are influenced by several cytokines, including tumour necrosis factor (TNF $\alpha)$, interleukin (IL) l, and IL6. Exercise has been shown to alter cytokine profiles, ${ }^{37}$ with most studies reporting an increase in IL6 levels. An increase in IL6 level is thought to inhibit the action of TNF $\alpha$ and ILl on osteoclasts and therefore might explain one possible mechanism by which exercises retard bone loss.

The ultimate goal of treating RA is to relieve pain and lessen inflammation, with a long term goal of limiting or preventing joint damage and disability. The development of effective new drug treatments has resulted in less focus on non-pharmacological modalities, such as exercise regimens. Nevertheless, a number of studies underline the concept that regular exercise programmes in RA have beneficial effects on the musculoskeletal system. Furthermore, there is no convincing evidence that they increase radiographic damage in these patients. The suggestion that exercises might also have a protective effect on the joints requires further study. Studies in the future, using more sensitive methods of assessing joint damage, such as ultrasound and magnetic resonance imaging, may help establish the important role of dynamic exercises in patients with RA.

Ann Rheum Dis 2004;63:1359-1361. doi: 10.1136/ard.2004.020693

\section{Authors' affiliations}

A P Anandarajah, E M Schwarz, University of Rochester Medical Center, Rochester, NY, USA

Correspondence to: Professor Asst A P Anandarajah, Allergy, Immunology and Rheumatology Unit, University of Rochester Medical Center, 601 Elmwood Avenue, Rochester, New York 14642, USA; Allen_Anandarajah@URMC.Rochester.Edu

\section{REFERENCES}

1 Van den Ende CHM, Vliet Vlieland TP, Munneke M, Hazes JM. Dynamic exercise therapy in rheumatoid arthritis: a systemic review. Br J Rheumatol 1998;37:677-87.

2 Goldring SR. Bone and joint destruction in rheumatoid arthritis: what is really happening? J Rheumatol 2002;29(suppl 65):44-8.

3 Arnett FC, Edworthy SM, Bloch DA, McShane DJ, Fries JF, Cooper NS, et al. The American Rheumatism Association 1987 revised criteria for the classification of rheumatoid arthritis. Arthritis Rheum 1988;31:315-24.

4 Van der Heijde DM. Joint erosions and patients with early rheumatoid arthritis. Br J Rheumatol 1995;34(suppl 2):74-8.

5 Wolfe F, Sharp JT. Radiographic outcome of recent-onset rheumatoid arthritis: a 19-year study of radiographic progression. Arthritis Rheum 1998;41:1571-82.

6 Plant MJ, Jones PW, Saklatvala J, Ollier WE, Dawes PT. Patterns of radiological progression in early rheumatoid arthritis: results of an 8 -year prospective study. J Rheumatol 1998;25:417-26.

7 Graudal NA, Jurik AG, de Carvalho A. Radiographic progression in rheumatoid arthritis: a long-term prospective study of 109 patients. Arthritis Rheum 1998:41:1470-80.

8 Wick MC, Lindblad S, Klareskog L, Van Vollenhoven RF. Relationship between inflammation and joint destruction in early rheumatoid arthritis: a mathematical description Ann Rheum Dis 2004;63:848-52. 
9 Jivoff L. Rehabilitation and rheumatoid arthritis Bull Rheum Dis 1975;26:838-41.

10 Mills J, Pinals R, Ropes M, Short CL, Sutcliffe J. Value of bed rest in patients with rheumatoid arthritis. N Engl J Med 1971;284:453-8.

11 Swezey R. Essentials of physical management and rehabilitation in arthritis. Semin Arthritis Rheum 1974;3:349-68.

12 Nordemar R, Ekblom B, Zachrisson L, Lundqvist K Physical training in rheumatoid arthritis. $A$ controlled long-term study, I. Scand J Rheumatol $1981 ; 10: 17-23$.

13 Minor MA, Hewett JE, Webel RR, Anderson SK, Kay DR. Efficacy of physical conditioning exercise in patients with rheumatoid arthritis and osteoarthritis. Arthritis Rheum 1989:32:1396-405.

14 Ekdahl C, Andersson SI, Moritz U, Svensson B. Dynamic versus static training in patients with rheumatoid arthritis. Scand J Rheumatol 1990; 19:17-26.

15 Stenstrom CH, Lindell B, Swanberg E, Swanberg P, Harms-Ringdahl K, Nordemar R. Intensive dynamic training in water for rheumatoid arthritis functional class II. A longterm study of effects. Scand J Rheumatol 1991:20:358-65.

16 Hakkinen A, Hakkinen K, Hannonen P. Effects of strength training on neuromuscular function and disease activity in patients with recent-onset inflammatory arthritis. Scand J Rheumatol 1994;23:237-42

17 Harkcom TM, Lampman RM, Banwell BF, Castor CW. Therapeutic value of graded 'exercise training in rheumatoid arthritis. Arthritis Rheum 1985;28:32-9.

18 Hansen TM, Hansen G, Langgaard AM, Rasmussen JO. Long-term physical training in rheumatoid arthritis. A randomized trial with different training programs and blinded observers. Scand J Rheumatol 1993;22:107-12.

19 van den Ende CHM, Hazes JM, le Cessie S, Mulder WJ, Belfor DG, Breedveld FC, et al. Comparison of high and low intensity training in well controlled rheumatoid arthritis. Results of a randomised clinical trial. Ann Rheum Dis 2000;59:798-805

20 van den Ende CHM, Breedveld FC, le Cessie S Dijkmans BA, de Mug AW, Hazes JM. Effect of intensive exercise on patients with active rheumatoid arthritis: a randomised clinical trial. Ann Rheum Dis 2000;59:615-621.

21 ACR. Guidelines for the management of rheumatoid arthritis. 2002 update. Arthritis Rheum 2002;46:328-46.

22 de Jong Z, Munneke M, Zwunderman AH, Kroon KH, Ronday KH, Lems WF, et al. Long term high intensity exercise and damage of small joints in rheumatoid arthritis. Ann Rheum Dis 2004;63:1399-1405.

23 Hakkinen A, Sokka T, Kotaniemi A, Hannonen P. A randomized two-year study of the effects of dynamic strength training on muscle strength, disease activity, functional capacity, and bone mineral density in early rheumatoid arthritis. Arthritis Rheum 2001;44:515-22.

24 Hakkinen A, Sokka T, Kautiainen H, Kotaniemi A, Hannonen P. Sustained maintenance of exercise induced muscle strength gains and normal bone mineral density in patients with early rheumatoid arthritis: a 5-year follow up. Ann Rheum Dis 2004:63:910-16.

25 Hakkinen A, Hakkinen K, Hannonen P. Effects of strength training on neuromuscular function and disease activity in patients with recent-onset inflammatory arthritis. Scand J Rheumatol 1994:23:237-42.

26 Nordemar R, Berg U, Ekblom B, Edstrom L. Changes in muscle fiber size and physical performance in patients with rheumatoid arthritis after 7 months physical training. Scand J Rheumatol 1976:5:233-8.

27 de Jong $Z$, Munneke $M$, Zwinderman $A H$, Kroon HM, Jansen A, Ronday KH, et al. Is a longterm high-intensity exercise program effective and safe in patients with rheumatoid arthritis? Arthritis Rheum 2003;48:2415-24.

28 O'Dell JR. Treating rheumatoid arthritis early: a window of opportunity? Arthritis Rheum 2002;46:283-5.
29 Van der Heide A, Jacobs JW, Bijlsma JW, Heurkens $\mathrm{AH}$, van Booma-Frankfort $\mathrm{C}$, van der Veen MJ, et al. The effectiveness of early treatment with "second-line" antirheumatic drugs: a randomized, controlled trial. Ann Intern Med 1996; 124:699-707

30 Egsmose C, Lund B, Borg G, Pettersson $H$, Berg $\mathrm{E}$, Brodin $U$, et al. Patients with rheumatoid arthritis benefit from early 2 nd line therapy. 5-year follow-up of a prospective double blind placebo controlled study. J Rheumatol 1995;22:2208-13.

31 Tsakonas $E$, Fitzgerald AA, Fitzcharles MA Cividino A, Thorne JC, M'Seffar A, et al. Consequences of delayed therapy with secondline agents in rheumatoid arthritis: a 3 year follow-up on the hydroxychloroquine in early rheumatoid arthritis (HERA) study. J Rheumatol 2000;27:623-9.

32 Wick MC, Anderwald C, Weiss RJ, Imhof $\mathrm{H}$, Kainberger F, Smolen JS. Radiological progression of joint damage in a longitudinal cohort of early DMARD-treated rheumatoid arthritis patients followed for 10 years. Scand J Rheumatol 2004;33:162-6.

33 James MJ, Cleland LG, Gaffney RD Proudman SM, Chatterton BE. Effect of exercise on 99Tc-DTPA clearance from knees with effusions. J Rheumatol 1994;21:501-4.

34 de Jong Z, Munneke M, Lems WF Zwinderman $\mathrm{AH}$, Kroon HM, Pauwels EK, et al. Slowing of bone loss in patients with rheumatoid arthritis by long-term high intensity exercise. Arthritis Rheum 2004;50:1066-76.

35 Haugeberg G, Orstavik RE, Kvein TK. Effects of rheumatoid arthritis on bone. Curr Opin Rheumatol 2003:15:469-75.

36 Compston JE, Vedi S, Croucher PI, Garrahan NJ, $\mathrm{O}^{\prime}$ Sullivan MM. Bone turnover in non-steroid treated rheumatoid arthritis. Ann Rheum Dis 1994;53:163-6.

37 Pedersen BK, Steensberg A, Fischer C. Exercise and cytokines with particular focus on muscle-derived IL-6. Exerc Immunol Rev 2001;7:18-31. 